\title{
Time matters: A stock-pollution approach to authorisation decision- making for PBT/vPvB chemicals under REACH
}

\author{
Silke Gabbert (corresponding author) \\ Wageningen University \\ Department of Social Sciences \\ Environmental Economics and Natural Resources Group \\ Hollandseweg 1, 6700 EW Wageningen, The Netherlands \\ Email: silke.gabbert@wur.nl \\ Phone: 0031317483870
}

Isabel Hilber

Agroscope

Institute for Sustainability Sciences

Environmental Analytics

Reckenholzstr. 191, CH-8046 Zurich 
Abstract:

A core aim of the European chemicals legislation REACH is to ensure that the risks caused by substances of very high concern (SVHC) are adequately controlled. Authorisation - i.e. the formal approval of certain uses of SVHC for a limited time - is a key regulatory instrument in order to achieve this goal. For SVHC which are, in addition to their toxicity, (very ) persistent and/or (very) bioaccumulative (PBT/vPvB chemicals), decision-making on the authorisation is conditional on a socio-economic analysis (SEA). In a SEA companies must demonstrate that the gains from keeping a chemical in use outweigh expected damage costs for society. The current setup of the REACH authorisation process, including existing guidance on performing a SEA, ignores that $\mathrm{PBT} / \mathrm{vPvB}$ chemicals are stock pollutants. This paper explores the implications of incorporating stock pollution effects of these chemicals into a SEA on authorisation decision-making. We develop a cost-benefit approach which includes stock dynamics of PBT/vPvB chemicals. This allows identifying the decision rules for granting or refusing an authorisation. Furthermore, we generalize the model to an entire set of damage functions. We show that ignoring stock pollution effects in a SEA may lead to erroneous decisions on the use of PBT/vPvB chemicals because long-term impacts are not adequately captured. Using a historic case of DDT soil contamination as an illustrative example, we discuss information requirements and challenges for authorisation decisions on the use of $\mathrm{PBT} / \mathrm{vPvB}$ chemicals under REACH.

Keywords: REACH, Substances of Very High Concern, authorisation, PBT/vPvB chemicals, socio-economic analysis, stock externalities. 


\section{$1 \quad$ Introduction}

A key objective of the new European chemicals legislation REACH (CEC 2006) is to ensure that the risks caused by 'substances of very high concern' (SVHC) are adequately controlled. What defines a 'concern' depends on chemicals' intrinsic properties. SVHC are chemicals which are classified as (i) carcinogenic, mutagenic or toxic for reproduction, (ii) persistent, bioaccumulative and toxic (PBT) or very persistent and very bioaccumulative (vPvB), (iii) substances that give "rise to an equivalent level of concern" like endocrine disrupting chemicals, or (iv) combinations of the criteria (i)-(iii) (CEC 2006, Article 57). The ultimate aim is to gradually replace SVHC by less harmful alternative chemicals or technologies, if this is considered "economically and technically viable" (CEC 2006, Article 55). From the list of SVHC the European Chemicals Agency (ECHA) can select particular harmful substances and include them in Annex XIV of the REACH legislation, a list of substances which are subject to authorisation (CEC 2006, Article 57, ECHA 2014a). The selection of SVHC and inclusion into this "candidate list" follows a pre-defined prioritisation scheme (ECHA 2014b, see also Gabbert et al. 2014 for a detailed review of the authorisation process). Currently, 169 chemicals have been identified as SVHC (ECHA 2014c). According to the "Roadmap on Substances of Very High Concern" all currently known SVHC shall be included on the candidate list by 2020 (ECHA 2013). Once a SVHC is included into Annex XIV, a "sunset date" is defined beyond which chemical companies may no longer produce, manufacture and market the chemical unless the European Commission has granted an authorisation permitting specific applied-for-uses (CEC 2006, Article 56).

If the risks from the continued use of the chemical cannot be adequately controlled, for example because safe concentration levels cannot be determined, an applicant must demonstrate by means of a socio-economic analysis (SEA) that 'socio-economic benefits' from using the chemical outweigh the 'risks' (i.e. expected damage costs) to human health and the environment (CEC 2006, Article 60-64). This "socio-economic application route" applies to chemicals which are, besides being toxic, persistent and/or bioaccumulative (PBT and $\mathrm{vPvB}$ chemicals), to chemicals classified as carcinogenic, mutagenic or toxic for reproduction in accordance with Directive 57/548/EEC (ECHA 2014b) and to chemicals with endocrine disrupting properties. For those SVHC where, to the contrary, an adequate control of risks can be demonstrated, a SEA is optional. 
The overall purpose of a SEA is to identify and assess all (expected) positive and negative impacts for human health and ecosystems arising from a continued use of the chemical. Applicants are required to identify alternative strategies, e.g. the replacement of a SVHC by another, less harmful chemical or technology, and to compare the impacts of such "non-use" scenarios (NU) with impacts of the "applied-for-use" (AFU) scenario (ECHA 2011). Authorisation of specific $\mathrm{PBT} / \mathrm{vPvB}$ uses can only be granted (i) if no alternative substances or technologies exist, and (ii) if the SEA can convincingly show that a continued use of the chemical will reveal positive net benefits to society. Thus, authorisation of PBT/vPvB chemicals is conditional on the results of the SEA.

In order to deliver meaningful results, the assessment of impacts in a SEA must adequately reflect the pollution patterns of the chemical(s) at hand. In particular, persistent chemicals differ from non-persistent ones by being 'stock pollutants'. Hence, with the on-going release, environmental concentrations increase over time. Stock pollutants, therefore, create an intertemporal pollution problem, of which impacts differ fundamentally from those of nonpersistent chemicals. Assessing stock externalities is a standard approach in environmental pollution control (see e.g. Keeler et al. 1972, Plourde 1972), with applications to pesticides (Conrad and Olson 1992), greenhouse gas emissions (Kolstad 1996b, Tahvonen 1997) or water contaminants (Roseta-Palma and Xepapadeas 2004). Looking into existing ECHA guidance documents on SEA we observe, however, that the need to account for stock pollution properties of $\mathrm{PBT} / \mathrm{vPvB}$ chemicals in a SEA has not been acknowledged. Rather, Annex XVI of the REACH legislation states that "the level of detail and scope of the SEA, or contributions to them, shall be the responsibility of the applicant for authorisation, or, in the case of a proposed restriction, the interested party". This is astonishing given the obvious differences of impacts between flow and stock pollutants in a SEA. Moreover, how stock pollution properties impact the decision-rule on the authorisation of persistent chemicals has not been explored so far.

In response to these fundamental gaps our paper develops a SEA model that explicitly accounts for stock pollution properties of persistent chemicals. We employ dynamic cost benefit analysis (CBA) for SEA, which is a widely used approach for assessing long-term impacts and risks (Söderquist et al. 2015, Ilg et al. 2016). Though modelling stock effects in pollution control problems is not new, existing studies usually assume a specific (e.g. a linear or a quadratic) damage function. We move beyond this standard approach by offering a generalized model that can be applied to any damage function. We also identify the decisionrules for granting or refusing authorisation to $\mathrm{PBT} / \mathrm{vPvB}$ chemicals. Although we address 
uncertainties by a sensitivity analysis we do not address irreversibilities and learning in our model. For such approaches we refer to Kolstad (1996a).

The paper is organised as follows. Section 2 develops a benchmark CBA model for SEA of $\mathrm{PBT} / \mathrm{vPvB}$ chemicals. We first introduce a continuous time model that allows projecting the pollution stock of a persistent chemical in a certain environmental compartment over time. To derive the decision rules for authorisation we incorporate stock dynamics in the CBA approach to assess impacts of $\mathrm{PBT} / \mathrm{vPvB}$ use and non-use. Furthermore, we generalize the standard CBA model to capture an entire class of damage functions. In section 3 we calibrate the model using data from a case-study in Nowshera, Pakistan, where a factory was producing dichlorodiphenyltrichloroethane (DDT) for more than three decades (1963-1994), causing massive DDT release to soil. Though DDT is a pesticide and does therefore not fall under the REACH legislation, it is one of the best explored persistent chemicals we know of. We therefore use DDT to illustrate the key features of the benchmark model, and to discuss important implications for authorisation decisions under REACH. Section 4 discusses results from the case study and summarises practical steps for applying a SEA for the authorisation of PBT/vPvB chemicals in REACH. Section 5 concludes.

\section{A benchmark model for socio-economic analysis of PBT/vPvB chemicals}

Besides the numerous benefits that chemicals have in modern daily life, their use can cause negative impacts to human health and the environment. Clearly, the type and severity of these impacts depend on the exposure concentration at a certain time. Contrary to chemicals that are purely toxic, persistent chemicals are known to poorly metabolise and degrade in ecosystems and biota. With on-going emissions, therefore, the concentration of a persistent chemical increases in environmental media and, consequently, exposure risks of biota and humans rise over time. There is overwhelming scientific evidence that persistent chemicals can cause multiple adverse environmental and human health effects, including a range of negative reproductive effects and pathological malformations in wild mammals and humans (Abelsohn et al. 2002, Loos et al. 2010, Langer 2010). These negative effects generate damage costs to society.

In the following we focus on environmental effects as they form the starting point for human exposure. If a persistent chemical remains in use, environmental exposure concentrations increase over time depending on the amount that is released into the environment $x$, which we assume in this paper to be constant, and the chemicals decay rate $\delta$ (Gabbert and Weikard 
2010). Increasing environmental concentrations over time create a pollution stock $P$. For analysing environmental impacts over time the analysis of the stock dynamics is essential. Following the standard environmental economics approach to pollution control, the relationship between the pollution stock $P$, emissions and the decay rate $\delta$ of the chemical can be illustrated by the following differential equation (e.g. Karp 2005):

$\dot{P}_{t}=x-\delta P$

$\dot{P}$ indicates its first-order derivative with respect to time, the change of the stock as a marginal unit of time elapses. According to Eq. (1) the change of pollution stock at any time $t$ depends on emissions minus the fraction of the stock that decays. The solution to this differential equation is (e.g. Sydsaeter et al. 2000):

$P_{t}=C e^{-\delta t}+\frac{x}{\delta}$

where $C$ is a constant. To determine the constant, consider $t=0$. From (2) we have

$P_{0}=C+\frac{x}{\delta}$

solving Eq. (3) for $C$ and substituting the result into (2) we obtain:

$P_{t}=\left(P_{0}-\frac{x}{\delta}\right) e^{-\delta t}+\frac{x}{\delta}=P_{0} e^{-\delta t}+\frac{x}{\delta}\left(1-e^{-\delta t}\right)$

It follows from Eq. (4) that the compartment-specific steady state is given by $\frac{x}{\delta}$. At any time $t$ the pollution stock $P_{t}$ depends on the initial stock $P_{0}$, the additional inflow of pollutants $x$ and the decay rate $\delta$. The latter parameter depends on and reflects the conditions of the compartment.

Companies who apply for authorisation of a PBT/vPvB use must "assess whether the socioeconomic benefits of continued use of the Annex XIV substance outweigh the risks to human health and the environment" (ECHA 2011). Thus, the applicant must demonstrate in a SEA that the value of positive impacts arising from the use of a PBT/vPvB exceeds the value of negative impacts. The use or non-use of $\mathrm{PBT} / \mathrm{vPvB}$ will cause different impacts (e.g. environmental impacts, impacts to human health, trade and employment, etc.). The problem how to balance different types of impacts depends on how impacts are valued (Gabbert et al. 2014). In the following we conceptualise the weighing of impacts as a standard cost-benefit analysis (CBA) approach where we assume that both expected benefits and risks, defined as 
expected impacts, of the continued use of a chemical can be evaluated and compared. Thus, expected impacts are transformed into expected damage costs. The appealing feature of this approach is that benefits and damage costs can be aggregated across all relevant categories, and the applied-for-use scenario can be expressed in terms of its net-present value (NPV), being the difference between (discounted) benefits and (discounted) damage costs. The NPV of the applied-for-use scenario can then be compared with the NPV of any other policy scenario (e.g. a complete ban of the chemical). Though the monetisation of all impacts may be challenging in practice (see Section 3), we use the CBA model as a benchmark model in order to analyse how stock dynamics can be incorporated in the socio-economic evaluation $\mathrm{PBT} / \mathrm{vPvB}$ use, and how this impacts the decision-making about the authorisation of these chemicals.

In our conceptual model we assume that production causes emissions, of which a fraction is released into the environment. In this way benefits of use depend on release $x$ :

$B_{t}(x)=b x$

This assumes a simple linear relationship with marginal benefits given by $b$. Damage costs depend on the pollution stock $P_{t}$, which in turn is a function of environmental release $x$ :

$D_{t}\left(P_{t}(x)\right)=\alpha P_{t}^{\beta}$

where $\alpha$ is a scaling factor and $\beta$ determines the curvature of the damage function. If $\beta=1$, damage costs are linear in the stock. If $\beta>1$, the damage function is convex and marginal damages increase over-proportionally in stock.

According to ECHA (2014) and the European Commission (2014) REACH applicants can apply for the authorisation of a specified use of a chemical, and for a limited period after which emissions have to stop (or a new application for authorisation has to be submitted). Note that, if a substance that is already regulated under the POP Regulation (Regulation (EC) No 850/2004) is included in Annex XIV to REACH, authorisations may only be granted under REACH in relation to uses exempted under the POP Regulation. Denoting the period of using a PBT/vPvB chemical with $T$, the NPV of the applied-for-use scenario is the difference between discounted benefits of use until $T$ and the sum of discounted damage costs until $T$ $(t \leq T$, "early damage costs"), and damage costs occurring after emissions ceased $(t>$ $T$, "late damage costs"): 
$N P V=\left(\int_{0}^{T} B_{t}(x) e^{-r t} d t-\int_{0}^{T} D_{t}\left(P_{t}(x)\right) e^{-r t} d t-\int_{T}^{\infty} D_{t}\left(P_{t}(x)\right) e^{-r t} d t\right)>0$,

where $r$ is the discount rate and $P_{t}$ is given by (4). Discounting transforms costs and benefits occurring at different periods into their present values (Weikard and Zhu 2005, Groom et al. 2005). This allows comparing benefits and damage costs of PBT/vPvB chemicals occurring at different periods. For a detailed discussion of the usefulness of different discounting approaches and the choice of the discount rate we refer to the environmental economics' literature (e.g. Gollier 2002, Hellweg et al. 2003, Gollier and Weitzman 2010).

Using the specifications in (5) and (6), integrating out and differentiating with respect to $T$ gives the following necessary condition for the optimal period of use $T$ :

$$
\begin{aligned}
& \left(b-\frac{\alpha \beta}{\delta \beta+r} P_{T}^{\beta-1}\right) e^{-r T}=0 \\
& \Leftrightarrow b=\frac{\alpha \beta}{\delta \beta+r} P_{T}^{\beta-1}
\end{aligned}
$$

Thus, contrary to earlier studies (e.g. Conrad and Olson 1992, Roseta-Palma and Xepapadeas 2004) our approach offers a decision-rule for the optimal period of use of persistent pollutants for an entire class of damage functions. The details to solving the maximisation problem are presented in the Appendix. If we assume the damage function to be linear (i.e. $\beta=1$ ), authorisation should be granted if

$b>\frac{\alpha}{\delta+r}$

Obviously, (10) is independent of $T$ and does not give us an optimal period of use. Hence, if marginal damages are linear in stock, authorisation of a PBT/vPvB chemical boils down to a "now or never" decision: If marginal benefits of use outweigh damage costs at the beginning of the assessment period (i.e. at $t=0$ ) they will exceed marginal damage costs at any $t$. In this case the PBT/vPvB chemical should remain in use for the entire period. If, to the contrary, marginal damage costs exceed marginal benefits at $t=0$ the chemical should be removed immediately. Generally, the more persistent the chemical (small value of $\delta$ ) the higher marginal benefits ought to be in order to warrant authorisation. This is equivalent to nonpersistent chemicals, though environmental concentrations in the optimum will of course be different.

For the case of a convex damage function (i.e. $\beta>1$ ), Eq. (9) can be re-arranged to 
$P_{T}=\left(\frac{b(\delta \beta+r)}{\alpha \beta}\right)^{\frac{1}{\beta-1}}$

Eq. (11) says that the optimal period of use $T$ is given by the time when a critical pollution level $P_{T}$ is reached which is described by the right hand side of (11). It is easy to see from (11) that the critical pollution level is higher when marginal benefits $b$ are higher, and when the decay $\delta$ and the discount rate $r$ are higher. Also, a higher damage function parameter $\alpha$ implies a lower critical pollution level. To further examine the optimal period of use we replace the left-hand side of (11) by (4). Notice that the right-hand side of (11) only consists of parameters. It is then convenient to define

$$
\left(\frac{b(\delta \beta+r)}{\alpha \beta}\right)^{\frac{1}{\beta-1}} \equiv \gamma
$$

Thus we obtain

$\frac{x}{\delta}+\left(P_{0}-\frac{x}{\delta}\right) e^{-\delta T}=\gamma$

Solving (13) for $T$ gives the optimal period of use $T^{*}$ :

$T^{*}=\frac{1}{\delta}\left(\ln \left(\frac{x}{\delta}-P_{0}\right)-\ln \left(\frac{x}{\delta}-\gamma\right)\right)$

It follows directly from (14) that an interior solution of the maximisation problem in (7), i.e. a positive optimal removal time $T^{*}$, depends on the values of $\gamma$ and $P_{0} . T^{*}$ is positive if and only if $\gamma>P_{0}$. In this case the use of a PBT/vPvB should be authorised for a duration given by $T^{*}$. For $\gamma \leq P_{0}$ we obtain a corner solution and authorisation should not be granted.

\section{Model calibration and implications for authorisation decisions of PBT/vPvB chemicals}

\subsection{Assessing stock dynamics}

The model developed in Section 2 provides the stopping rules for PBT/vPvB use given stock pollution properties. Although stock dynamics of persistent pollutants have been studied in the past, it has so far not been acknowledged in the setup of the REACH authorisation process that $\mathrm{PBT} / \mathrm{vPvB}$ chemicals are stock pollutants. As a consequence, this property has not been explicitly captured by regulatory rules. Our model offers the analytic response to this 
challenge. The model can be applied by applicants, who must demonstrate that authorisation of a certain PBT/vPvB use is warranted, and by regulatory authorities and their committees (e.g. the ECHA Committees for Risk Assessment (RAC) and for Socio-Economic Assessment (SEAC)) who are involved in the authorisation decision-process.

In order to illustrate how stock pollution properties can be incorporated into a SEA, we use a historic case of DDT release. For DDT a large number of studies have been conducted during the past decades examining the intrinsic properties of DDT and its effects on the environment and biota. Notwithstanding, uncertainties remain, for example regarding the degradation halflife, which is typical for $\mathrm{PBT} / \mathrm{vPvB}$ chemicals and must also be addressed in a SEA. Therefore, although REACH does not apply to pesticides and there is a worldwide ban of the agricultural use of DDT under the Stockholm Convention (Stockholm Convention, 2008), we use DDT as proof-of-concept case to calibrate our model and for discussing implications from incorporating stock pollution properties in a SEA for $\mathrm{PBT} / \mathrm{vPvB}$ authorisations under REACH.

The case study concerns a DDT producing factory in Amman Garh near Nowshera, Pakistan (former North West Frontier Province (NWFP)). Between 1963 and 1994 an annual amount of 700 tons of technical DDT was produced (Khwaja et al. 2006). During the production period of the factory, DDT was extensively and mainly released to soil and a small amount into the water channels and freshwater compartments surrounding the site. Generally, the pollution stock can be assessed for different environmental compartments such as soil, sediment, freshwater, or air. The partitioning of a chemical in different compartments can be simulated with a Level III fugacity model developed by, for instance, the Canadian Centre for Environmental Modelling and Chemistry (Webster et al. 2005) or by the CliMoChem model suggested in Schenker et al. (2008). Since our focus is on the conceptual problem how stock pollution properties of $\mathrm{PBT} / \mathrm{vPvB}$ chemicals can be embedded in a SEA to support regulatory decision-making, such multi-media assessment is beyond the scope of this paper. Therefore, we start with a simple local pollution problem using data about DDT measured concentrations in soil documented by Younas et al. (2013). Implications from our assessment with regard to a broader spatial analysis will be discussed in section 4 .

Chemicals that fall into the PBT/vPvB category have similar chemico-physical properties like DDT, of which their high hydrophobicity (octonol-water partition coefficient $\left(\mathrm{K}_{\mathrm{OW}}\right)$ for some organochlorine pesticides (e.g. DDT) are $\log \mathrm{K}_{\mathrm{OW}} 5$ to 7; Shen and Wania, 2005) and their 
high affinity to organic carbon (organic carbon partition coefficient for DDT range from log $\mathrm{K}_{\mathrm{OC}} 4.7-\log \mathrm{K}_{\mathrm{OC}} 5.2$; ATSDR, 2002) are most prominent. Thus, PBT/vPvB chemicals are strongly bound to soil where they remain in the surface layers and hardly leach into groundwater (ATSDR, 2002). The chemicals can be only transported with soil particles or particulate matter they are bound to (ATSDR, 2002). Therefore, in our case study we assume that $100 \%$ of DDT was released to soil. This assumption seems adequate unless DDT would be largely released into water, which was not the case.

Using Eq. (4) we simulate stock dynamics of DDT in soil for a period of 50 years, i.e. from 1963 to 2013, taking into account an emission period of 31 years (from 1963 to 1994). We assume that of the yearly amount of DDT production a fraction of $0.25 \%$ o was released to the surrounding soil. This spill rate was calculated from the mean concentrations measured on the factory site in 2005 (Jan et al., 2009). Concentrations in soil were calculated based on EUSES (Lijzen and Rikken 2004) default assumptions for the mass of soil (Table 1).

Table 1: Basic data for assessing DDT release into the soil surrounding the factory in Nowshera

\begin{tabular}{|c|c|c|}
\hline Parameters assessed & Data & Study \\
\hline Operation period of the factory & $\begin{array}{c}1963(t=0)-1994 \\
(t=T)\end{array}$ & Khwaja 2006 \\
\hline Emission period [years] & 31 & Khwaja 2006 \\
\hline Background concentration $\left[\mathrm{g}_{\mathrm{DDT}} / \mathrm{t}_{\mathrm{soil}}\right]$ & 0.1 & Younas et al. 2013 \\
\hline $\begin{array}{l}\text { Steady-state concentration of DDT in soil } \\
{\left[\mathrm{g}_{\mathrm{DDT}} / \mathrm{t}_{\mathrm{soil}}\right]}\end{array}$ & $\begin{aligned} 239.42(\text { for } \delta & =0.3) \\
1561.49(\text { for } \delta & =0.05)\end{aligned}$ & Own calculations \\
\hline Polluted area $\left[\mathrm{m}^{2}\right]$ & 9328 & Younas et al. 2013 \\
\hline Polluted soil depth $[\mathrm{m}]$ & 0.2 & EU 2008 \\
\hline Polluted soil volume $\left[\mathrm{m}^{3}\right]$ & 1866 & own calculations \\
\hline Soil density $\left[\mathrm{kg} / \mathrm{m}^{3}\right]$ & 1300 & own calculations \\
\hline Polluted soil mass $\left[\mathrm{t}_{\text {soil }}\right]$ & 2425 & own calculations \\
\hline Annual DDT production volume [metric tonnes] & 700 & Khwaja 2006 \\
\hline DDT spill rate [\%o] & 0.25 & Jan et al. 2009 \\
\hline
\end{tabular}

For assessing stock dynamics we assumed that the releases were evenly distributed across the area. Thus, for given emissions and DDT spill the release of DDT during the operation period of the factory was calculated to be $0.198 \mathrm{~g}_{\mathrm{DDT}} /\left(\mathrm{t}_{\mathrm{soil}} *_{\mathrm{day}}\right)$. After the factory had shut down in 1994 the daily release turned to zero. The initial stock $P_{0}$ was assumed to be equal to the 
highest background concentration of $0.1 \mathrm{~g}_{\mathrm{DDT}} / \mathrm{t}_{\text {soil }}$ (Younas et al., 2013). The decay rate of DDT in soils varies considerably. A literature survey revealed values for the degradation halflife lying between 0.06 and 30 years, for which corresponding decay rates can be calculated (Table 2).

Table 2: Degradation half-lives and decay rates reported for DDT and its metabolites in soil

\begin{tabular}{l|c|c|c|c|c}
\multicolumn{1}{c|}{ Study } & Compound & Soil type & Climate zone & $\begin{array}{c}\text { Degradation } \\
\text { half-life [years] }\end{array}$ & $\begin{array}{c}\text { Decay rate } \\
{\left[\mathbf{y}^{-1}\right]}\end{array}$ \\
\hline \hline ATSDR, 2002 & $\sum$ DDT $^{\text {a) }}$ & Tropical & $\begin{array}{c}\text { Tropics to } \\
\text { subtropics }\end{array}$ & $0.06-0.9$ & $11.8-0.8$ \\
\hline ATSDR, 2002 & DDE & Tropical & $\begin{array}{c}\text { Tropics to } \\
\text { subtropics }\end{array}$ & $0.4-0.7$ & $1.7-0.9$ \\
\hline ATSDR, 2002 & DDE & Acidic & n.a. & $>1.8$ & $<0.4$ \\
\hline ATSDR, 2002 & DDDT & Temperate & Temperate & $2.3-15$ & $0.3-0.04$ \\
\hline ATSDR, 2002 & DDT & Temperate & Temperate & 5.3 & 0.13 \\
\hline $\begin{array}{l}\text { Szeto and Price, } \\
1991\end{array}$ & DDT & Muck & Mountains & 14.6 & 0.05 \\
\hline $\begin{array}{l}\text { Dimond and } \\
\text { Owen, 1996 }\end{array}$ & DDT & Forest & Temperate & $20-30$ & $0.03-0.02$ \\
\hline
\end{tabular}

${ }^{\text {a)}}$ SDDT: DDT and dichlorodiphenyldichlorethene (DDE) and dichlorodiphenyldichlorethane (DDD).

Following Eq. (4), the analysis of stock dynamics is based on estimates about the initial stock $\left(P_{0}\right)$, release $(x)$ and the decay rate $(\delta)$. These parameters are subject to uncertainty as robust estimates are often lacking. In particular, $\delta$ can vary widely for different climates and soils and, hence, the assessment of this parameter in the laboratory under controlled conditions may not adequately capture conditions in the field (Fenner et al. 2013; Mackay et al. 2001). In the case study we therefore performed an analysis of stock dynamics for the lowest and highest decay rate in temperate and mountain regions according to the data reported in Table 2 that were 0.3 per year (corresponding to a degradation half-life of 2.3 years) and 0.05 per year (corresponding to a degradation half-life of 15 years), respectively. Figure 1 illustrates stock dynamics for DDT for both decay rates. The curves for the low and the high decay scenario delineate the corridor for the expected change of stock over time. The corridor, therefore, visualizes the uncertainty of stock dynamics due to the uncertain decay rate. 


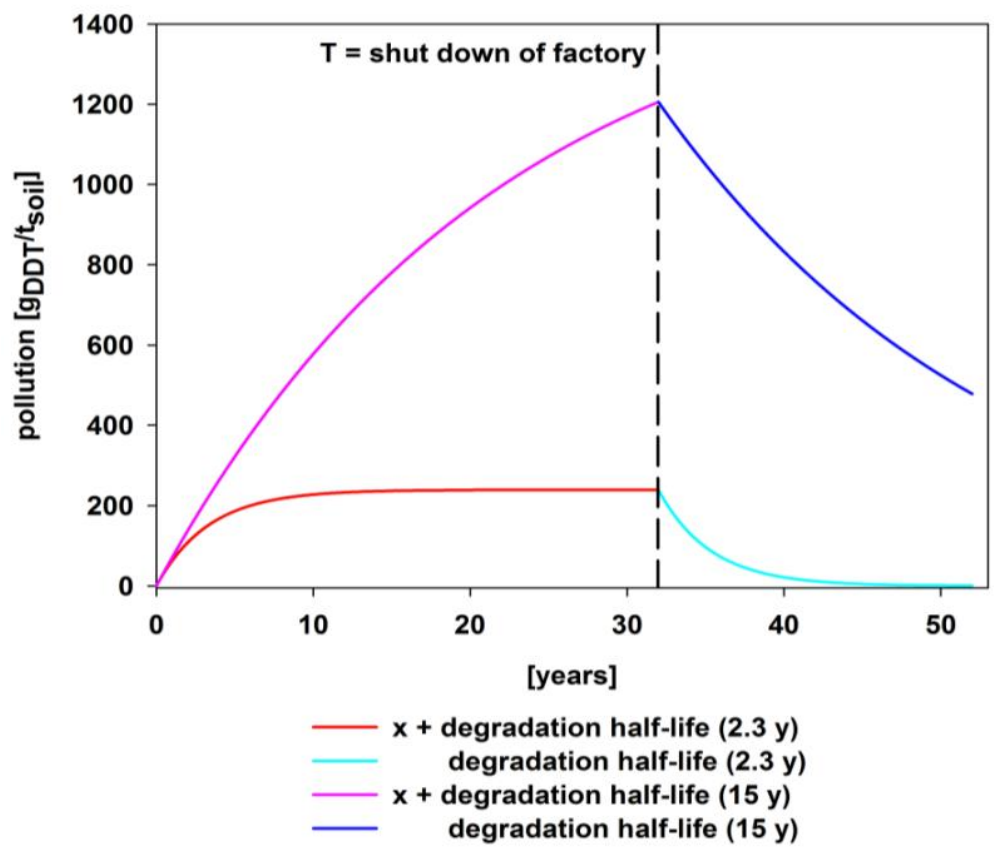

Figure 1: Stock dynamics for DDT release in soil for a high and a low degradation half-life Source: Own calculations.

Since the initial DDT concentration in soil is below the steady state concentration (see Table 1), a constant release causes the pollution stock in both decay scenarios to increase (see pink and orange line). The change of stock over time is non-linear. Note that for the low decay scenario (i.e. a high degradation half-life of DDT, pink line in Figure 1), which represents the upper bound of the expected environmental stock, the steady state had not been reached when the factory closed. In contrast, for the high decay scenario (i.e. low degradation half-life, orange line in Figure 1) concentrations in soil had converged to the steady state before the factory had closed. At the steady state level the inflow of DDT into soil per period equals decay. After the factory closed in 1994 ( $T$, see dashed line in Figure 1) no additional DDT was released into soil. Consequently, the pollution stock starts to decline. For the low decay scenario, however, the fraction of DDT that degrades per year is much smaller compared to the high decay scenario. In both scenarios DDT remained in soil for several years after emissions ceased.

\subsection{Determining the optimal period of use}

Determining the critical stock $P_{T}$ above which a chemical must no longer be used, and the corresponding optimal period of use $T^{*}$ (see Eq. (11) and (14)) requires to specify the 
parameters which translate stocks into damage values, i.e. $\alpha$ and $\beta$ (Eq. (11) in combination with Eq. (7)).

Ideally, damage function parameters could be estimated from empirical data. This requires first to explore the relationship between exposure concentrations (as predicted in the stock dynamics assessment) and observed environmental and health impacts. A possible follow-up step could then be to perform impact-specific valuation studies, based on discovered or stated preference methods (see, for instance, Loomis et al. 2000, Travisi and Nijkamp 2008), which reveal monetary damage values for different impacts. As a final step, a (linear or non-linear) regression model can be fitted into the scatter plot of valued impacts to estimate the scaling factor $\alpha$ and the damage parameter $\beta$. Although this approach offers conceptual and methodological rigour, the case of DDT illustrates that its operationalization in a SEA for authorisation is not always straightforward.

First, empirical information on health and environmental impacts of $\mathrm{PBT} / \mathrm{vPvB}$ chemicals is often uncertain or lacking. Although for DDT a large number of studies have been published about the monitoring of DDT uptake in food (Lichtenstein 1973, Hilber et al. 2008), feed (Willett et al. 1993), marine animals (Jensen et al. 1969), and mammals including humans (Kelly et al. 2004, Bouwman et al. 2011), the link between soil contamination and health impacts could be established over the whole food web and its variety. Likewise, we found controversial evidence on impacts of DDT and its metabolites on soil dwelling organisms such as bacteria, algae, funghi, and soil fauna (e.g. Mitra and Raghu 1998, Megharaij et al. 2000, Edvantoro et al. 2003,). Still, a transfer of DDT and metabolites into plants and thus into the feed and food web already occurs at low soil concentrations (max. $3 \mathrm{~g}_{\mathrm{DDT}} / \mathrm{t}_{\text {soil }}$, Willett et al. 1993, Hilber et al. 2008, Aslund et al. 2010). Moreover, empirical evidence about negative health impacts due to exposure to DDT turns out to be inconclusive (ATSDR 2002, Asmus et al. 2008).

Second, chemical-specific valuation studies exist only for very few chemicals (e.g. nitrate, see e.g. Buzby et al. 1998, Lichtenberg and Zimmermann 1999). Point estimates of national external costs of pesticides published in, for example, Pimentel (2005), Tegtmeier and Duffy (2004), and Pretty and Waibel (2005), are not related to time-sensitive concentration levels in environmental media and humans and are, therefore, of little use for estimating the scaling factor $\alpha$ and for gaining insight into the convexity of the damage function, given by $\beta$. 
In the absence of sufficient empirical evidence about concentration-related impacts and damage costs value transfer is a secon-best option. Table 3 summarizes all data used for calibrating our model. We used estimates of external costs per $\mathrm{kg}$ of pesticide use as provided in Leach and Mumford (2008). For the U.S., the UK and Germany mean external costs were estimated to be 8.78 Euros per $\mathrm{kg}$ pesticide use (Table 3) and reflect different types of impacts (e.g. drinking water contamination, pollution incidents, biodiversity or wildlife losses, negative impacts on tourism and landscape, bee colony losses, and acute effects to human health). This estimate was transferred to external costs per unit of pesticide use in Pakistan by means of GDP-proportionate extrapolation (Table 3, row 5). We calculated external costs per $\mathrm{kg}$ of DDT pollution stock, obtaining an approximation of the scaling factor $\alpha$. For model calibration we assumed the damage function to be quadratic, thus $\beta=2$ (Table 3, row 7). Marginal benefits $b$ were calculated assuming that profits are a fraction (20\%) of annual market revenues as documented in Khjawa (2006). Again, this value was related to DDT pollution released to soil. Clearly, the numerical results for the economic parameters $\alpha$ and $\beta$ are just rough estimates and are reported to illustrate our method.

Table 3: Data used for calibrating the benchmark model

\begin{tabular}{|c|c|}
\hline Initial stock $\left(P_{0}\right)\left[\mathrm{g}_{\mathrm{DDT}} / \mathrm{t}_{\mathrm{soil}}\right]^{\mathrm{a}}$ & 0.1 \\
\hline Total DDT release from factory (production volume * spill rate) $[\mathrm{kg} / \mathrm{year}]$ & 175 \\
\hline Release $(x)\left[\mathrm{g}_{\mathrm{DDT}} /\left(\mathrm{t}_{\text {soil }} * \text { day }\right)\right]^{\mathrm{b}}$ & 0.198 \\
\hline $\begin{array}{l}\text { Damage costs of an average pesticide based on cost assessments for } \\
\left.\left.\text { Germany, the UK and the USA [Euro/( } \mathrm{kg}_{\mathrm{ai}}{ }^{*} \text { year }\right)\right]^{\mathrm{c}}\end{array}$ & 8.78 \\
\hline $\begin{array}{l}\text { GDP-adjusted damage costs of an average pesticide in Pakistan } \\
\left.\left[\text { Euro/( } \mathrm{kg}_{\mathrm{ai}}{ }^{*} \text { year }\right)\right]^{\mathrm{c}}\end{array}$ & 0.025 \\
\hline $\begin{array}{l}\text { Damage costs per unit of pollution, scaling factor } \\
(\alpha)\left[(\text { Euro/day }) /\left(\mathrm{g}_{\mathrm{DDT}} / \mathrm{t}_{\text {soil }}\right)^{\beta}\right] \text {, with } \beta=2\end{array}$ & 0.6 \\
\hline Convexity parameter damage function $(\beta)[-]^{a}$ & 2.0 \\
\hline Market revenue DDT in Pakistan [Euro/t $\mathrm{DDT}^{*}$ year $]^{\mathrm{b}}$ & 54174.4 \\
\hline Marginal benefits $(b)\left[\text { Euro } /\left(\mathrm{g}_{\mathrm{DDT}} / \mathrm{t}_{\mathrm{soil}}\right)\right]^{\mathrm{a}}$ & 150.58 \\
\hline
\end{tabular}

Assuming a degradation half-life of 2.3 years the critical stock $P_{T}$, where marginal costs of DDT use start to exceed marginal benefits, is very small $\left(0.2 \mathrm{~g}_{\mathrm{DDT}} / \mathrm{t}_{\mathrm{soil}}\right)$ but slightly above the 
initial stock of $0.1 \mathrm{~g}_{\mathrm{DDT}} / \mathrm{t}_{\text {soil }} 1$. According to Eq. (14) the corresponding optimal period of use $T^{*}$ is 0.6 days. Thus, for the hypothetical case that the factory in Nowshera would have applied for authorisation suggesting the emission path shown in Figure 1 the model reveals that DDT production should in fact not have been permitted. However, if the company reduces emissions, for example by adopting abatement measures which reduce DDT release, authorisation could have been granted for certain periods. Figure 2 shows the authorisation period as a function of abatement in terms of a consecutive reduction of the spill rate by $30 \%$ for a low degradation half-life (blue curve) and a high degradation half-life (red curve).

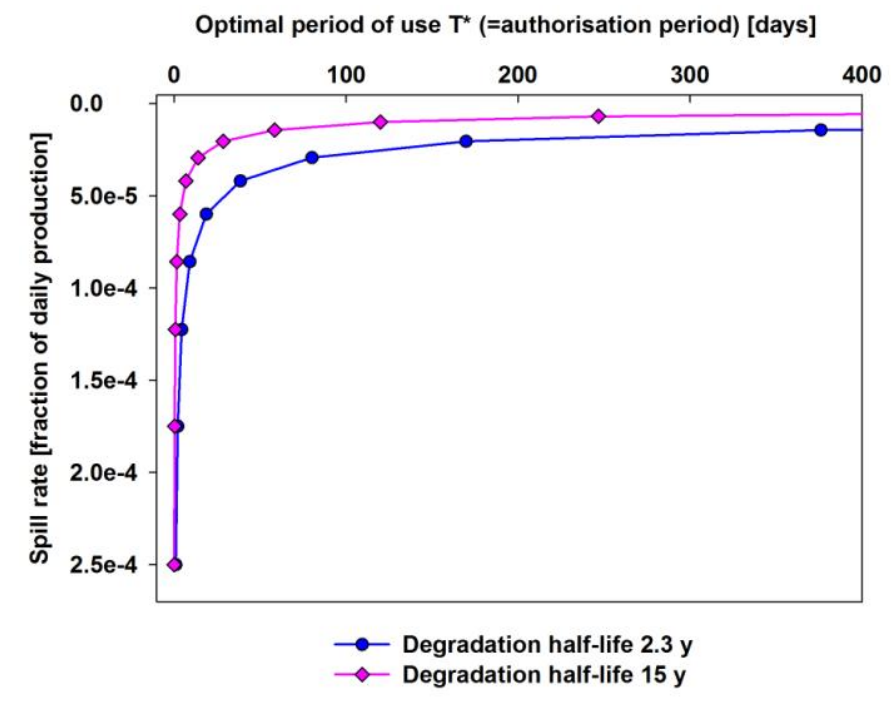

Figure 2: Optimal period of use $\left(T^{*}\right)$ depending on DDT spill

Source: Own calculations.

Finally, if a monetised damage cost assessment is not wanted or is considered unfeasible the critical stock - and, hence, the optimal period of use - can be determined by linking stock dynamics with policy parameters (e.g. screening values, maximum tolerable risk levels, minimum risk levels, serious risk levels for human intake or environmental media etc.), which offer impact-specific upper target concentrations beyond which exposure is considered to cause serious health or environmental damage. Using screening values for DDT in soil as published, for example, in Carlon (2007, ranging from $1 \mathrm{~g}_{\mathrm{DDT}} / \mathrm{t}_{\text {dry }}$ weight (dw) soil (Finland) to 4 $\mathrm{g}_{\mathrm{DDT}} / \mathrm{t}_{\mathrm{dw}}$ soil (Netherlands), we observe that, irrespective of the assumed decay scenario, concentrations in soil exceeded these values already after five and four days, respectively. After 30 years of DDT-production the expected pollution stock, as well as soil concentrations 
observed in later sampling studies (Khwaja et al. 2007, Jan et al. 2009), was several orders of magnitude above the screening values (Figure 1).

\subsection{Sensitivity analysis}

In addition to uncertainty about stock dynamics parameters the optimal period of use $T^{*}$ is subject to uncertainty about economic parameters, due to incomplete or lacking information about exposure-dependent impacts from $\mathrm{PBT} / \mathrm{vPvB}$ use and corresponding damage cost values. A SEA for $\mathrm{PBT} / \mathrm{vPvB}$ chemicals must, therefore, be accompanied by a detailed sensitivity analysis which has to be based on a careful specification of worst- and best-case scenarios for key parameters in order to capture the entire range of possible outcomes. For the illustrative case of DDT pollution in Nowshera, Table 4 shows the optimal period of use $T^{*}$ for different values of $\alpha$ (the scaling factor of the damage function, see Eq. (6)) and $\beta$ (the exponent of the damage function) under the high and the low degradation half-live scenario.

Table 4: Optimal period of use $T^{*}$ for DDT

depending on damage function parameters $\alpha$ and $\beta$, and the decay rate $\delta$

\begin{tabular}{|c|c|c|c|c|c|c|}
\hline & \multicolumn{6}{|c|}{ Optimal period of use $T^{*}$ [days] } \\
\hline & \multicolumn{3}{|c|}{$\begin{array}{c}\qquad \delta=0.3 \\
\text { Degradation half-life } 2.3 \text { years }\end{array}$} & \multicolumn{3}{|c|}{$\begin{array}{c}\qquad \delta=0.05 \\
\text { Degradation half-life } 15 \text { years }\end{array}$} \\
\hline & $\begin{array}{c}\alpha=6 \\
{\left[\text { Euro } /\left(\mathrm{g}_{\mathrm{DDT}} / \mathrm{t}\right.\right.} \\
\text { soil })]\end{array}$ & $\begin{array}{c}\alpha=0.6 \\
{\left[\text { Euro/(g } \text { g }_{\text {DDT }} / t\right.} \\
\text { soil })]\end{array}$ & $\begin{array}{c}\alpha=0.06 \\
{\left[\text { Euro } /\left(\mathrm{g}_{\mathrm{DDT}} / \mathrm{t}\right.\right.} \\
\text { soil })]\end{array}$ & $\begin{array}{c}\alpha=6 \\
{\left[\text { Euro } /\left(\mathrm{g}_{\mathrm{DDT}} / \mathrm{t}\right.\right.} \\
\text { soil })]\end{array}$ & $\begin{array}{c}\alpha=0.6 \\
{\left[\text { Euro } /\left(g_{\mathrm{DDT}} / \mathrm{t}\right.\right.} \\
\text { soil })]\end{array}$ & $\begin{array}{c}\alpha=0.06 \\
{\left[\text { Euro/(g }\left(\mathrm{g}_{\mathrm{DDT}} / \mathrm{t}\right.\right.} \\
\text { soil })]\end{array}$ \\
\hline$\beta=1.0$ & 0 & 0 & $\infty$ & 0 & 0 & 0 \\
\hline$\beta=1.5$ & 0 & 0 & 23.2 & 0 & 0 & 0 \\
\hline$\beta=2.0$ & 0 & 0.05 & 10.3 & 0 & 0 & 1.4 \\
\hline$\beta=2.5$ & 0 & 1.28 & 7.9 & 0 & 0.05 & 2.1 \\
\hline$\beta=3.0$ & 0.2 & 1.81 & 6.9 & 0 & 0.45 & 2.5 \\
\hline
\end{tabular}

Source: Own calculations.

Generally, the optimal period of use is lower for more persistent chemicals. This is obvious because environmental exposure and, hence, damage, is higher for PBT/vPvB chemicals with a low decay rate (high degradation half-life). Moreover, the optimal period of use increases with decreasing $\alpha$. Thus, for given marginal benefits of use a PBT/vPvB chemical may remain in use longer if damage costs are lower. This result is robust for a range of values for $\beta$, and for both decay rate scenarios. Furthermore, it can be observed that increasing $\beta$ has 
ambiguous effects. For a high decay rate and small $\alpha$, i.e. when the threshold stock is large, higher $\beta$ implies a shorter period of use. For low decay rates and sufficiently high $\alpha$ the time of use increases in $\beta$. Finally, for a linear damage function $(\beta=1)$ we find the "now or never" policies as discussed in Section 2.

\section{$5 \quad$ Conclusions and policy implications}

This paper argues that regulatory control decisions under the European chemicals legislation REACH must adequately capture the pollution patterns of PBT/vPvB chemicals, which are a sub-group of "Substances of Very High Concern”. Specifically, persistent chemicals are stock pollutants and can, therefore, remain in the environment for very long periods.

Under REACH the authorisation process has been introduced to control the risks of SVHC use. Authorisation decisions for PBT/vPvB chemicals are conditional on a SEA, comparing benefits of on-going use with damages to human health and the environment. In this paper we show how stock pollution properties of PBT/vPvB chemicals can be incorporated into a SEA. We introduce a CBA benchmark model where the damage cost function captures stock dynamics of $\mathrm{PBT} / \mathrm{vPvB}$ chemicals. We determine the general decision rules for granting or refusing an authorisation. The model also allows identifying a compartment-specific critical pollution level above which a chemical should be removed from the market. In addition, we offer an extension of standard economic stock pollution models which allows determining the optimal period of use for a class of damage functions with different degrees of convexity. We calibrate the model for an illustrative case study of DDT soil pollution in Nowshera, Pakistan.

Although our model and the illustrative case study are based on a number of simplifying assumptions, it reveals interesting insights that have implications for the setup of the REACH authorisation process. First, the decision rules for the authorisation of PBT/vPvB chemicals differ fundamentally from those for non-persistent chemicals. In contrast to non-persistent chemicals, where authorisation only depends on instantaneous benefits and damages, damage costs of $\mathrm{PBT} / \mathrm{vPvB}$ chemicals consist of both early damage costs (i.e. damage costs during use) and late damage costs (i.e. damage costs after emissions stopped). Ignoring stock pollution effects in a SEA would disregard long-term damages and, consequently, may severely underestimate overall damage costs. 
Second, whether or not and how long a PBT/vPvB chemical may remain in use crucially depends on the shape of the damage function. For the specific case of a linear damage function (i.e. constant marginal damage costs) authorisation decisions boil down to "now-ornever' decisions where chemicals should either remain in use or should be removed immediately. For non-linear damage functions an interior solution, i.e. a finite period of use within which marginal benefit exceed marginal costs, exists. For given marginal benefits the optimal period of use depends on stock pollution parameters (i.e. the initial stock $P_{0}$, emissions $x$, the compartment-specific decay rate $\delta$ ) and the economic parameters in the damage function (i.e. the scaling factor $\alpha$, the parameter denoting the convexity of the damage function $\beta$, and the discount rate $r$ ). To conduct a meaningful SEA for PBT/vPvB chemicals, therefore, requires detailed guidance to applicants how to estimate these parameters, and how to define best- and worst cases for sensitivity analysis.

Our approach does not claim to solve immediately all empirical and practical problems related to applications of SEA, however, the CBA benchmark model identifies conceptual and informational requirements. Further research should, for instance, examine how to assess stock dynamics in different compartments and for different spatial scales to capture the entire range of damages from $\mathrm{PBT} / \mathrm{vPvB}$ use in a SEA. As we illustrate for the case of the local DDT soil pollution problem in Nowshera, Pakistan, the link between exposure concentrations and health or environmental impacts, which can be irreversible (e.g. Kolstad 1996a), is often difficult or impossible to establish without additional analyses. However, just as with the REACH registration process, the burden of proof to attain authorisation for a specific SVHC use is on the applicants' side. As a consequence, it is the task of producers, manufacturers and importers to provide, and, where necessary, to generate data that facilitate the authorisation decision. It is, however, the responsibility of the regulator to clearly define information requirements for a concern-driven regulation that accounts for stock externalities. 


\section{Appendix}

Constant release of a PBT/vPvB chemical causes environmental concentrations to accumulate over time. The pollution stock at time $t$ is given by the following equation:

$P_{t}=\frac{x}{\delta}+\left(P_{0}-\frac{x}{\delta}\right) e^{-\delta t}$

where $x$ is the amount released into the environment (e.g. into soil), $\delta$ denotes the decay rate of the chemical, and $P_{0}$ is the initial concentration. After emissions ceased the stock starts to degrade, the environmental concentration at $t \geq T$ is given by:

$P_{t}=P_{T} e^{\delta(T-t)}$

The objective of an authorisation is to find the period of use that maximizes the NPV of chemical's use:

$N P V=\left(\int_{0}^{T} B(x) e^{-r t} d t-\int_{0}^{T} D_{t}\left(P_{t}(x)\right) e^{-r t} d t-\int_{T}^{\infty} D_{t}\left(P_{t}(x)\right) e^{-r t} d t\right)>0$,

where $D_{t}\left(P_{t}(x)\right)$ is equal to $\alpha P_{t}^{\beta}$.

With constant release $x$ the maximum NPV is revealed if marginal benefits equal marginal damage costs:

$\frac{\partial N P V}{\partial T}=\frac{\partial}{\partial T}\left(\int_{0}^{T} B(x) e^{-r t}-\int_{0}^{T} D\left(P_{t}(x)\right) e^{-r t}-\int_{T}^{\infty} D\left(P_{t}(x)\right) e^{-r t}\right) d t=0$.

Integrating benefits out gives

$\int_{0}^{T} B(x) e^{-r t} d t=\frac{B(x)}{r}\left(1-e^{-r T}\right)$

Differentiating (A.5) with respect to $T$ using $B(x)=b x$ gives

$\frac{\delta}{\delta T}\left(\frac{B(x)}{r}\left(1-e^{-r T}\right)\right)=b x e^{-r T}$,

where $b$ denotes marginal benefits. Inserting (A.6) into (A.4) we obtain

$b x e^{-r t}-\frac{\delta}{\delta T}\left(\int_{0}^{T} D\left(P_{t}(x)\right) e^{-r t}-\int_{T}^{\infty} D\left(P_{t}(x)\right) e^{-r t}\right) d t=0$ 
which simplifies to

$b x e^{-r T}-D_{t}\left(P_{t}\right) e^{-r T}+D_{t}\left(P_{T}\right) e^{-r T}-\int_{T}^{\infty} \frac{\partial}{\partial T} D\left(P_{t}(x)\right) e^{-r t} d t=0$.

Replacing $D_{t}\left(P_{t}\right)$ in A8 by $\alpha P_{t}^{\beta}$ reveals

$b x e^{-r T}-\int_{T}^{\infty} \frac{\partial}{\partial T}\left(\alpha P_{t}^{\beta}\right) e^{-r t} d t=0$

Differentiating the last expression in (A.9), using A.2, we obtain

$b x e^{-r T}-\int_{T}^{\infty} \alpha \beta P_{t}^{\beta-1}\left(\frac{\partial P_{T}}{\partial T} e^{\delta(T-t)}+P_{T} \delta e^{\delta(T-t)}\right) e^{-r t} d t=0$.

Since $\frac{\partial P_{t}}{\partial T}=x-\delta P_{T}$, Eq. (A.10) simplifies to

$b x e^{-r T}-\int_{T}^{\infty} \alpha \beta P_{t}^{\beta-1} x e^{\delta(T-t)-r t} d t=0$

$\Leftrightarrow b x e^{-r T} \alpha \beta x \int_{T}^{\infty} P_{T}^{\beta-1} e^{\delta(\beta-1)(T-t)+\delta(T-t)-r t} d t=0$

$\Leftrightarrow b x e^{-r T}-\alpha \beta x P_{T}^{\beta-1} \int_{T}^{\infty} e^{\delta \beta T} e^{-(\delta \beta+r) t} d t=0$

$\Leftrightarrow b x e^{-r T}-\alpha \beta x P_{T}^{\beta-1} e^{\delta \beta T} \frac{e^{-(\delta \beta+r) T}}{(\delta \beta+r)}=0$

$\Leftrightarrow b x e^{-r T} \frac{-\alpha \beta x P_{T}^{\beta-1}}{\delta \beta+r} e^{\delta \beta T} e^{-(\delta \beta+r) T}=0$

$\Leftrightarrow\left(b x-\frac{\alpha \beta x}{\delta \beta+r} P_{T}^{\beta-1}\right) e^{-r T}=0$,

which gives Eq. (9). 


\section{Acknowledgements}

We wish to thank Rudi Weikard for helpful comments to an earlier draft of this paper. Financial support from the Swiss National Science Foundation for a Joint Research Project between Pakistan and Switzerland (Project No. IZ70Z_123957/1) is gratefully acknowledged.

\section{References}

Abelsohn, A., Gibson, B.L., Sanborn, M.D., Weir, E., 2002. Identifying and managing adverse environmental health effects: 5. Persistent organic pollutants. Canadian Med. Ass. J. 166(12), 1549-1554.

Aslund, M.L.W., Lunney, A.I., Rutter, A,. Zeeb, B.A., 2010. Effects of amendments on the uptake and distribution of DDT in Cucurbita pepo ssp pepo plants. Env. Poll. 158 (2), 508-513.

Asmus, C., Alonzo, H.G.A., Palacios, M., da Silva, A.P., Filhote, M.I.D., Buosi, D., Camara, V.D., 2008. Assessment of human health risk from organochlorine pesticide residues in Cidade dos Meninos, Duque de Caxias, Rio de Janeiro, Brazil. Cadernos De Saude Publica 24, 755-766.

ATSDR, 2002. Toxicological profile for DDT, DDE, and DDD. Agency for Toxic Substances and Disease Registry, Atlanta, Georgia, USA.

Bouwman, H., van den Berg, H., Kylin, H., 2011. DDT and Malaria Prevention: Addressing the Paradox. Env. Health Persp. 119, 744-747.

Buzby, J.C., Fox, J.A., Ready, R.C., Crutchfield, S.R., 1998. Measuring Consumer Benefits of Food Safety Risk Reductions. J. of Agr. and Appl. Econ. 30(1), 69-82.

Carlon, C., 2007. Derivation methods of soil screening values in Europe. A review and evaluation of national procedures towards harmonisation. JRC Scientific and Technical Reports EUR 22805EN, JRC, Ispra, Italy.

CEC, 2006. Regulation (EC) No. 1907/2006 of the European Parliament and the Council of 18 December 2006 concerning the Registration, Evaluation, Authorisation and Restriction of Chemicals (REACH), establishing a European Chemicals Agency, amending Directive 1999/45/EC and repealing Council Regulation (EEC) No. 793/93 and Commission Regulation (EC) No 1488/94 as well as Council Directive 76/769/EEC and Commission Directives 91/155/EEC, 93/67/EEC. 93/105/EC and 2000/21/EC. http://eur-lex.europa.eu/LexUriServ/LexUriServ.do?uri=OJ:L:2006:396:0001:0849:EN:PDF～(accessed 01.07.16).

Conrad, J.M., Olson, L.J., 1992. The economics of a stock pollutant: Aldicarb on Long Island. Env. and Res. Econ. 3, 245-258.

Diamond, J.B.; Owen, R.B., 1996. Long-term residue of DDT compounds in forest soils in Maine. Env. Poll. 92(2), 227-230.

Edvantoro, B.B., Naidu, R., Megharaj, M., Singleton, I., 2003. Changes in microbial properties associated with long-term arsenic and DDT contaminated soils at disused cattle dip sites. Ecotox. and Env. Safety 55, 344-351.

European Chemical Agency (ECHA), 2011. Guidance on the preparation of an application for authorisation. Version 1, January 2011. ECHA, Helsinki, Finland.

European Chemical Agency (ECHA), 2013. SVHC Roadmap to 2020 Implementation Plan. ECHA, Helsinki, Finland.

European Chemical Agency (ECHA), 2014a. Candidate List of Substances of Very High Concern for Authorisation. http://echa.europa.eu/web/guest/candidate-list-table (accessed 05.04.14).

European Chemical Agency (ECHA), 2014b. Prioritisation of substances of very high concern (SVHCs) for inclusion in the Authorisation List (Annex XIV). ECHA, Helsinki, Finland. 
European Chemical Agency (ECHA), 2014c. Applications for authorisation. ECHA, Helsinki.

http://echa.europa.eu/web/guest/regulations/reach/authorisation/applications-for-authorisation (accessed 01.07.16).

European Commission, 2014. REACH and the Stockholm Convention as well as the UNECE Protocol: A Common Understanding. http://ec.europa.eu/DocsRoom/documents/5805/attachments/1/translations/en/renditions/native (15.08.14).

Council of the European Commission, 2013. Roadmap on Substances of Very High Concern. Document 5867/13, European Commission, Brussels, Belgium.

Fenner, K., Canonical, S., Wackett, L.P., Elsner, M., 2013. Evaluating pesticide degradation in the environment: blind spots and emerging opportunities. Science 341, 752-758.

Gabbert, S., Weikard, H.-P., 2010. A Theory of Chemicals Testing and Regulation. Nat. Res. Forum 34(2), $155-$ 164.

Gabbert, S., Scheringer, M., Ng, C.A., Stolzenberg, H.-C., 2014. Socio-economic analysis for the authorisation of chemicals under REACH: A case of very high concern? Reg. Tox. and Pharm. 70, 564-571.

Gollier, C., 2002. Time horizon and the discount rate. Journal of Economic Theory 107, 463-473.

Gollier, C., Weitzman, M.L., 2010. How should the distant future be discounted when discount rates are uncertain? Econ. Letters 107, 350-353.

Groom, B., Hepburn, C., Koundouri, P., Pearce, D., 2005. Declining discount rates: the long and the short of it. Environmental and Resource Economics 32, 445-493.Jan, M. R.; Shah, J.; Khawaja, M. A.; Gul, K., DDT residue in soil and water in and around abandoned DDT manufacturing factory. Env. Mon. and Assess. 2009, 155(1-4), 31-38.

Hellweg. S., Hofstetter, T.B., Hungerbuehler, K., 2003. Discounting and the environment: Should current impacts be weighted differently than impacts harming future generations? The Int. J. of Life Cycle Assess. 8(1), 8-18.

Hilber, I., Maeder, P., Schulin, R., Wyss, G.S., 2008. Survey of organochlorine pesticides in horticultural soils and there grown Cucurbitaceae. Chemosphere 73, 954-961.

Ilg, P., Gabbert, S., Weikard, H.-P., 2016. Nuclear Waste Management under Approaching Disaster: A Comparison of Decommissioning Strategies for the German Repository Asse II. Risk Analysis, in press (DOI DOI: 10.1111/risa.12648).

IPEN, 2009. DDT in eggs: A global review. IPEN Pesticides Working Group. http://www.ipen.org/documents/ddt-eggs-global-review (accessed 15.09.14).

Jan, M.R., Shah, J., Khawaja, M.A., Gul, K., 2009. DDT residue in soil and water in and around abandoned DDT manufacturing factory. Env. Mon. and Assess. 155, 31-38.

Jensen, S., Johnels, A.G., Olsson, M., Otterlind, G., 1969. DDT and PCB in marine animals from Swedish waters. Nature 224, 247-250.

Karp, L., Zang, J., 2005. Regulation of Stock Externalities with Correlated Abatement Costs. Env. \& Res. Econ. 32, 273-299.

Keeler, E., Spence, M., Zeckhauser, R., 1971. The optimal control of pollution. J. of Econ. Theory 4, 19-34.

Kelly, B.C., Gobas, F.A.P.C., McLachlan, M.S., 2004. Intestinal absorption and biomagnification of organic contaminants in fish, wildlife, and humans. Env. Tox. and Chem. 23, 2324-2336.

Khwaja, M.A., Jan, M.R., Gul, K., 2006. Physical verification and study of contamination of soil and water in and surrounding areas of abandoned persistent organic pollutant (DDT) factory in North West Frontier Province (NWFP) Pakistan. Sustainable Development Policy Institute SDPI, Institute of Chemical Sciences, Peshawar University, Islamabad, Pakistan.

Khwaja, M.A.; Jan, M.R.; Gul, K., 2007. Study of contamination of soil in surrounding of abandoned persistant organic pollutant (DDT) factory in North West Frontier Province (NWFP) Pakistan. Sustainable Development Policy Institute (SDPI), Institute of Chemical Sciences, Peshawar University: Islamabad, Pakistan.

Kolstad, C.D., 1996a. Fundamental irreversibilities in stock externalities. J. of Publ. Econ. 60, 221-233. 
Kolstad, C.D., 1996b. Learning and Stock Effects in Environmental Regulation: The Case of Greenhouse Gas Emissions. J. of Env. Econ. and Man. 31(1), 1-18.

Langer, P., 2010. The impacts of organochlorines and other persistent pollutants on thyroid and metabolic health. Frontiers in Neuroendocrinology 31(4), 497-518.

Leach, A.W., Mumford, J.D., 2008. Pesticide Environmental Accounting: A method for Assessing the external costs of individual pesticide applications. Env. Poll. 151, 139-147.

Lichtenberg, E., Zimmermann, R., 1999. Adverse Health Experiences, Environmental Attitudes, and Pesticide Usage of Farm Operators. Risk Anal. 19(2), 283-294.

Lijzen, J.P.A., Rikken, M.G.J., 2004. EUSES 2.0. European System for the Evaluation of Substances. RIVM Report No. 601900005/2004, RIVM, Bilthoven, The Netherlands.

Loomis, J., Kent, P., Strange, L., Fausch, K., Covich, A., 2000. Measuring the total economic value of restoring ecosystem services in an impaired river basin: results from a contingent valuation study. Ecol. Econ. 33(1), 103-117.

Loos, R., Locoro, G., Comero, S., Contini, S., Schwesig, D., Werres, F., Balsaa, P., Gans, O., Weiss, S., Blaha, L., Bolchi, M., Gawlik, B.M., 2010. Pan-European survey on the occurrence of selected polar organic persistent pollutants in ground water. Water Res. 44(14), 4115-4126.

Mackay D., McCarty L.S., MacLeod, M., 2001. On the validity of classifying chemicals for persistence, bioaccumulation, toxicity and potential for long range transport. Env. Tox. and Chem. 20, 1491-1498.

Megharaij, M., Kantachote, D., Singleton, I., Naidu, R., 2000. Effects of long-term contamination of DDT on soil microflora with special reference to soil algae and algal transformation of DDT. Env. Poll. 109(1), $35-42$.

Mitra, J., Raghu, K., (1998): "Long term DDT pollution in tropical soils: Effect of DDT and degradation products on soil microbial activities leading to soil fertility." Bulletin of Environmental Contamination and Toxicology 60 (4), 585-591.

Pimentel, D., 2005. Environmental and Economic Costs of the Application of Pesticides Primarily in the United States. Env., Devel. and Sust. 7(2), 229-252.

Plourde, C.G., 1972. A model of waste accumulation and disposal. Can. J. of Econ. 5, 199-225.

Pretty, J., Waibel, H., 2005. Paying the Price: The Full Cost of Pesticides. In: Pretty, J. (ed.): The Pesticide Detox, Earthscan, London, pp. 39-54.

Roseta-Palma, C., Xepapadeas, A., 2004. Robust control in water management. J. of Risk. and Uncer. 29(1), 2134.

Schenker, U., Scheringer, M., Hungerbühler, K., 2008. Investigating the Global Fate of DDT: Model Evaluation and Estimation of Future Trends. Env. Sci. \& Techn. 42(4), 1178-1184.

Shen, L., Wania F., 2005. Compilation, evaluation, and selection of physical-chemical property data for organochlorine pesticides. J. of Chem. and Engin. Data 50, 742-768

Söderqvist, T., Brinkhoff, P., Norberg, T., Rosen, L., Back, P.-E., Norrman, J., 2015. Cost-benefit analysis as part of sustainability assessment of remediation alternatives for contaminated land. J. of Env. Man. 157, 267-278.

Stockholm Convention, 2008. Stockholm convention on persistent organic pollutants. http://www.pops.int, (accessed 01.07.16).

Sydsaeter, K, Strom, A, Berck, P., 2000. Economists’ Mathematical Manual. Berlin: Springer.

Szeto, S.Y.; Price, P.M., 1991. Persistence of pesticide residues in mineral and organic soils in the Fraser Valley of British Columbia. J. of Agr. and Food Chem. 39(9), 1679-1684.

Tahvonen, O., 1997. Fossil fuels, stock externalities, and backstop technology. The Can. J. of Econ. 30(4a), 855874.

Tegtmeier, E.M., Duffy, M.D., 2004. External Costs of Agricultural Production in the United States. Int. J. of Agr. Sust. 2(1), 1-20.

Travisi, C.M., Nijkamp, P., 2008. Valuing environmental and health risk in agriculture: A choice experiment approach to pesticides in Italy. Ecol. Econ. 67(4), 598-607. 
Webster, E., Mackay, D., Wania, F., Arnot, J., Gobas, F., Gouin, T., Hubbarde, J., Bonnell, M., 2005. Development and Application of Models of Chemical Fate in Canada Modelling Guidance Document. CEMN Report No. 200501, Trent University, Ontario, Canada.

Weikard, H.-P., Zhu, X., 2005. Discounting and environmental quality: When should dual rates be used? Econ. Model. 22, 868-878.

Willett, L.B., Odonnell, A.F., Durst, H.I., Kurz, M.M., 1993. Mechanisms of movement of organochlorine pesticides from soils to cows via forages. J. of Dairy Sci. 76, 1635-1644.

Younas, A.; Hilber, I.; Rehman, S.; Khwaja, M.A.; Bucheli, T.D., 2013. Former DDT-factory revisited for remediation: Severe DDT concentrations in soils and plants from within the area. Env. Sci. and Poll. Res. 20, 1966-1976. 